\title{
Breast self-examination and associated factors among women in Wolaita Sodo, Ethiopia: a community-based cross- sectional study
}

\author{
Temesgen Lera ${ }^{1 *}$ (D, Aman Beyene ${ }^{2}$, Befekadu Bekele ${ }^{1}$ and Solomon Abreha ${ }^{1}$
}

\begin{abstract}
Background: The early detection of breast cancer plays an important role in decreasing morbidity and mortality of breast cancer. Breast self-examination (BSE) is one screening method used for the early detection of breast cancer. BSE involves the woman looking at and feeling each breast for possible lumps, distortions, or swellings. BSE is a simple exercise that can potentially save women's lives, but BSE receives relatively little attention and no study has yet addressed BSE at the community level. Here we assessed BSE and associated factors among women aged 2065 years in Wolaita Sodo city, Ethiopia.
\end{abstract}

Methods: This was a community-based, cross-sectional study. Systematic random sampling was used to select 626 women aged 20-65 years old. Data were collected using a pre-tested and structured questionnaire. Data were recorded using EpiData version 3.5.1 and exported to SPSS version 21 for cleaning and statistical analysis. Bivariable analysis was performed, and variables with a $p$-value $<0.25$ were used in multiple logistic regression analysis. Multiple logistic regression was employed, and variables with $p$-values $<0.05$ were considered statically significant.

Results: A total of 629 women aged between 20 and 65 years were included in the study. Over half (60.9\%) of participants were aged between 20 and 29 years, and $8.2 \%$ were $<50$ years old. Women who mentioned BSE as a method for the early detection of breast problems were 6.36-times (95\% Cl: 3.72, 10.71) more likely to perform BSE than those who reported that they did not know of any method. Those who had breast fed for 13-24 months were 2.43 times $(95 \% \mathrm{Cl}: 1.28,4.59)$ more likely to examine their breasts than those who breast fed for different durations or used other methods. Employed study participants were 3.13-times $(95 \% \mathrm{Cl}: 1.14,8.58)$ more likely to practice BSE than those who were not employed. Likewise, students were 3.73 -times $(95 \% \mathrm{Cl}: 1.19,11.73)$ more likely to perform BSE.

Conclusions: In our sample, women's practice of BSE was relatively low. Knowledge of BSE, breastfeeding up to 24 months, being employed, and being a student were factors affecting performing BSE. Educating girls and increasing awareness, including through electronic media, are important to encourage BSE and improve breast cancer outcomes.

Keywords: Breast self-examination (BSE), Breast cancer, Wolaita Sodo, Ethiopia

\footnotetext{
* Correspondence: temesgenlera@yahoo.com

${ }^{1}$ School of Public Health, Wolaita Sodo University, Wolaita, Ethiopia

Full list of author information is available at the end of the article

C C The Author(s). 2020 Open Access This article is licensed under a Creative Commons Attribution 4.0 International License, which permits use, sharing, adaptation, distribution and reproduction in any medium or format, as long as you give appropriate credit to the original author(s) and the source, provide a link to the Creative Commons licence, and indicate if changes were made. The images or other third party material in this article are included in the article's Creative Commons licence, unless indicated otherwise in a credit line to the material. If material is not included in the article's Creative Commons licence and your intended use is not permitted by statutory regulation or exceeds the permitted use, you will need to obtain permission directly from the copyright holder. To view a copy of this licence, visit http://creativecommons.org/licenses/by/4.0/. The Creative Commons Public Domain Dedication waiver (http://creativecommons.org/publicdomain/zero/1.0/) applies to the data made available in this article, unless otherwise stated in a credit line to the data.
} 


\section{Plain English summary}

Detecting breast cancer early is important for decreasing its associated morbidity and mortality. Breast selfexamination (BSE) is a screening method used to detect breast cancer early. In this study, respondents were asked via a closed-ended structured questionnaire conducted through face-to-face interviews whether or not they practiced breast self-examination regularly. Six hundred twenty-nine women participated, with a response rate of $100 \% .76 \%$ of study participants were married, and $49.8 \%$ percent of women were housewives. We found that the prevalence of BSE among this sample of women was $34.5 \%$. Knowledge of BSE, breastfeeding up to 24 months, being employed, and being a student were factors associated with performing BSE. Therefore, educating girls and increasing awareness, including through electronic media, are important to encourage BSE and improve breast cancer outcomes.

\section{Background}

Breast cancer is an issue of public health importance in both developed and developing nations. Due to its high prevalence, breast cancer places significant pressure on health system resources and incurs significant healthcare costs. Breast cancer is the second leading cause of death among women globally, more than a million new cases detected yearly, accounting for $10.9 \%$ of all cancer cases, second to lung cancer $[1,2]$. Its occurrence is growing both in developed and developing regions. An estimated 636,000 new cases were identified in high-resource countries, while 514,000 cases were identified in lowand middle-resource countries in 2008. Breast cancer is the most recurrent cause of death among women both in developing and developed counties, with an estimated 269,000 and 189,000 losses, respectively. Seventy percent of all breast cancer cases will be in low- and middleresource countries by 2020 [3] globally. The occurrence of breast cancer varies across the African region, ranging from 19.3 per 100,000 per year in Eastern Africa to 38.1 per 100,000 per year in Southern Africa [4].

Breast self-examination (BSE) is a breast cancer screening method that involves the woman looking at and feeling her own breasts for possible lumps, distortions, or swellings. BSE is a simple exercise that can potentially save women's lives. BSE is recommended for every woman from the age of 20 years onwards, and BSE is recommended to be performed for $20 \mathrm{~min}$ every month [5]. However, women in developing countries are known not to perform BSE for various reasons [1]. A woman who performs BSE may be more motivated to seek medical attention, including clinical breast examination (CBE) and mammography [6].

In Ethiopia, over half of women with breast cancer are aged 50 and younger. It has been shown that $69.6 \%$ of patients ignore their initial symptoms for an average of over 1.5 years [7]. BSE is still recommended as a general approach to increasing breast health awareness and detecting any anomalies because it is free, painless, and easy to practice [5]. Furthermore, the American Cancer Society also recommends that women, from age 20, should be educated on the advantages and disadvantages of performing monthly BSE [8].

Breast cancer in low- to middle-income countries tends to present late and has poor clinical outcomes due to several factors such as unequal access to prompt high-quality treatment and a lack of early screening [3]. Despite the fact that breast cancer has recently become a leading cause of mortality in young women, especially those in urban areas, the Ethiopian health system has traditionally concentrated on communicable disease prevention as a public health priority [7]. Furthermore, there are very few reports measuring BSE at the population level. Here we addressed this knowledge gap by assessing BSE and its associated factors in women aged 20-65 years in Wolaita Sodo city, Ethiopia, to identify the need for information on BSE in Ethiopia.

\section{Methods}

\section{Study setting and design}

The study was carried out in Wolaita Sodo city. The city has a total population of 250,521 (male 79,871 (52\%), female $73,650(48 \%))$, and the city has three sub-cities, 18 kebeles, three health centers, one Ministry of Healthowned hospital, and one private hospital. The city is located $160 \mathrm{~km}$ from the regional city Hawassa and 327 $\mathrm{km}$ from Addis Ababa, the capital of Ethiopia [9]. A community-based cross-sectional study design was employed.

\section{Source population}

All women aged 20-65 years were considered as a source population.

\section{Study population}

Houses in selected kebeles were included by systematic random sampling, and study unit was selected by the simple random sampling technique.

\section{Inclusion and exclusion criteria}

Women age 20-60 years were included in the study, and women who were seriously ill during the period of data collection, had known breast cancer, and those not willing to participate in the study were excluded.

\section{Sample size and sampling procedure}

Sample size was calculated with EPidata statistical software version 3.03 using the single population proportion statistical formula: 


$$
\mathrm{N}=\mathrm{Z}(1.96)^{2} \mathrm{P}(1-\mathrm{P}) / \mathrm{d}^{2}
$$

with the assumptions $\mathrm{z}=1.96$ at a $95 \%$ confidence level; the P-prevalence of BSE was taken as 53.6\% (0.536) from a previous study [10]; and the non-response rate was $10 \%$, confidence levels of $95 \%$, and a $5 \%$ margin of error.

Therefore, the calculated sample size was 572 and, after considering a $10 \%$ non-response rate, the final sample size was 629 .

\section{Sampling procedure}

Multi-stage sampling was used to select study respondents. First, among the 18 kebeles in the city, 6 kebeles were randomly selected by simple random sampling to represent all kebeles. The source population in each selected kebele was identified from Wolaita Sodo Finance Economic Development Department data [9]. The sample size allocated to the selected kebeles was proportional to the source population in the kebele. The sampling interval was calculated by diving the source population by our sample $[(\mathrm{N} / \mathrm{n})=15,098$ / $629=24]$. The first household was selected by simple random sampling from 1 to 24 listed households, and the 10th household was chosen randomly.

Sampling frame (household)-containing lists of the population in the selected kebeles were obtained, and every 24th house was visited to select the study population by systematic random sampling until reaching the intended sample size for a given kebele. The respondents from each selected household were taken by simple random sampling whenever there was more than one eligible woman in a selected household (Fig. 1).

\section{Data collection procedure}

Structured, pre-tested, and interviewer-administered questionnaires were used. The questions included sociodemographic characteristics and BSE-related issues. The questionnaires were adapted from the Ethiopian Development and Health Survey (EDHS) and the published literature. Data were collected between 24 November 2018 and 2 December 2018 by trained data collectors. Data were collected through face-toface interviews, maintaining the pre-determined sampling intervals. The data collectors informed the respondents about all the details of the research and procedures, what was expected of them, and the potential risks and benefits in order to encourage accurate and honest responses. When the woman was not available at the first visit, data collectors arranged alternative visits. If a woman was still not available on second visits or declined to participate, the household was skipped and the immediate next household in the sampling frame was considered.

\section{Data quality management}

Before data collection, the questionnaire was first prepared in English and translated into Amharic and back to English to maintain consistency. Data collectors and supervisors received 2 days of training by the principal investigator before data collection.

A pre-test was conducted in Dilbetigil kebele, which was not one of the selected kebeles, and 5\% of the total sample size was tested. Based on the pre-test, questionnaires were revised, edited, and necessary corrections made. Daily checks of data for completeness and consistency were performed during data collection.

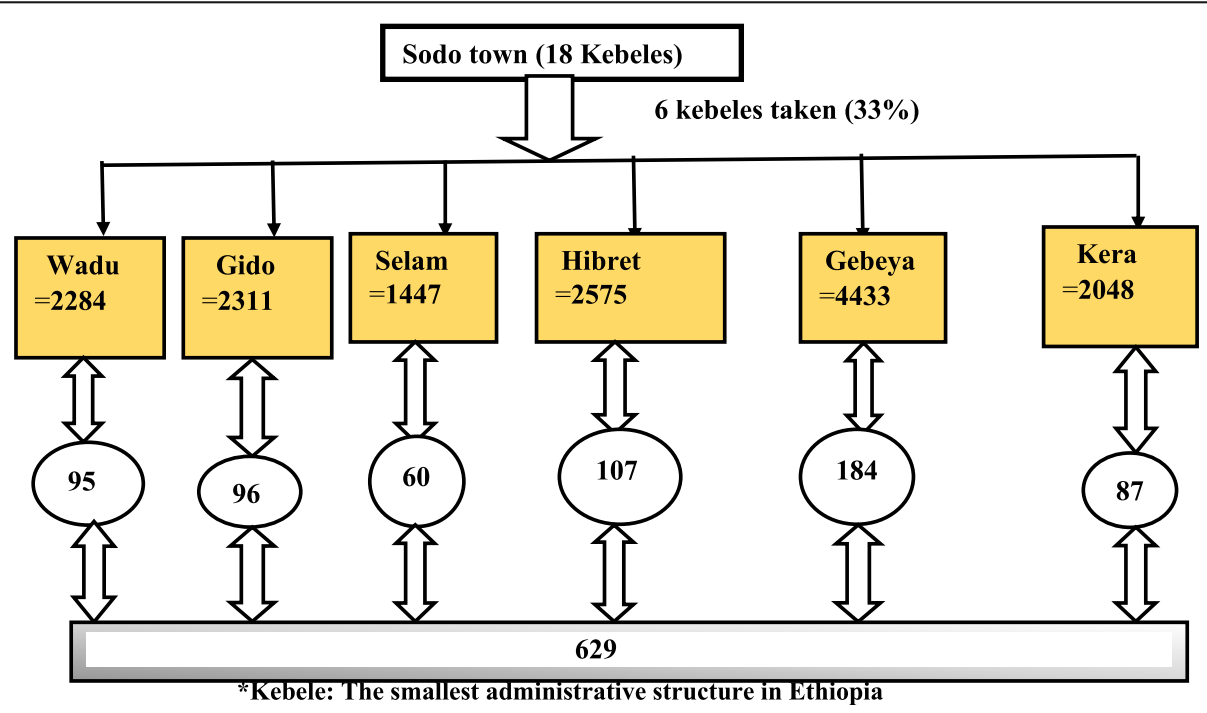

Fig. 1 Sampling procedure of the study 


\section{Data analysis procedures}

Data were entered into EpiData version 3.1 and cleaned to check for accuracy, consistency, completeness, and values, and any identified error was corrected.

Data were exported into SPSS version 21 (IBM Statistics, Chicago, IL) for analysis. Descriptive statistics were performed. Bivariable analyses were computed, and variables with $p$-values $<0.25$ were considered candidates for multiple logistic regression analysis. Multiple logistic regression analysis was performed, and variables with $\mathrm{p}$ values $\leq 0.05$ were considered statistically significant. Adjusted odds ratios (AOR) with 95\% confidence intervals (CI) were calculated.

\section{Ethical issues}

Ethical clearance was obtained from Wolaita Sodo University Institutional Review Board (IRB). Written permission was obtained from Sodo City Health Department. During data collection, all respondents were asked for permission, and informed consent was obtained from each study participant.

\section{Operational definitions \\ Breast self-examination (BSE)}

The self-examination of the breasts to identify any changes in the breasts [11].

\section{Breast self-examination performed}

If the woman performed BSE at least once in the last 12 months.

\section{Age 20 to 65}

American Cancer Society-recommended BSE for women aged 20 or older, and mammography for women aged 40 or older [8].

\section{Results}

\section{Sociodemographic characteristics of the subjects}

Six hundred and twenty-nine women were interviewed and subjected to analysis. The participants were aged between 20 and 65 years. $60.9 \%$ of participants were aged $20-29$ years, and $8.2 \%$ were aged over 50 years. Eightyseven percent of participants were Wolaita in ethnicity, and $70.6 \%$ were protestant. Three hundred and thirtyeight respondents had completed secondary education, and 478 study participants were married (Table 1 ).

\section{Knowledge and practice of BSE and information sources}

Among the respondents, 94\% knew (heard or read) about breast cancer and their main source of information was electronic media (62.4\%). The contribution of health professionals as a source of breast cancer information was found to be $14.7 \%$. Electronic media, family/ friends, and health workers were reported as major sources of information. Forty five respondents reported receiving information on breast cancer from other sources like journals, books, and non-governmental organizations (Fig. 2).

The reported methods of breast cancer screening were clinical breast examination (45.3\%) and BSE (18\%) and $36.5 \%$ women responded that they did not know of any method of breast cancer screening. Of those who had heard about breast cancer, 46\% had also heard about BSE and, among study participants who had received information on BSE, 79.8\% had performed BSE and 71.6\% reported they regularly performed it. Among those who had ever heard of breast cancer, 92\% knew (heard) their family history of breast cancer (Table 2).

\section{Knowledge of the right age to perform BSE and the reasons given to perform BSE}

Those performing BSE had different perspectives on the correct age to commence BSE, which should be between 10 and 30 years of age (mean age $18.41 \pm 2.8 \mathrm{SD}$ ). Of these, 63 recommended BSE at 20 years and 144 responded "I don't know". Of those who had performed BSE, 107 respondents reported no specific time/any time they could remember, and 133 reported practicing it on a regular basis (Table 3 ).

\section{Reasons for not performing BSE}

Of respondents who had ever heard of BSE, 45 believed that they had some kind of barrier to practicing BSE. However, over half of performers $(54.8 \%)$ claimed that there was no obstacle to performing BSE (Fig. 3).

\section{Distribution of spousal/parents support to perform BSE and the need of information on BSE}

Spousal and other support for BSE was $67.2 \%$. However, $88 \%$ of BSE performers were confident in performing self-examination. Almost all study participants (98.6\%) knew early detection of breast cancer improved the chances of survival. 91\% of respondents wanted more information about BSE. Within the year before this study, among performers of BSE, 149 participants performed it more than six times and 26 participants did it four to six times (Table 4).

\section{Factors associated with BSE}

Bivariate binary logistic regression analysis revealed that occupational status, duration of breastfeeding, female education, husband's education, early detection method for breast cancer, source of information, and knowledge of personal history of having a benign breast lump were candidates for multiple logistic regression analysis at $p \leq$ 0.25 .

In the multivariable logistic regression analysis, occupational status of women, duration of breastfeeding, and 
Table 1 Sociodemographic characteristics of the women in Wolaita Sodo, $2019(n=629)$

\begin{tabular}{|c|c|c|c|}
\hline & & & \\
\hline Variables/characteristics & Frequency (\%) & Variables/characteristics & Frequency (\%) \\
\hline Age distribution of the women & & Duration of breastfeeding & \\
\hline 20-29 years & $383(60.9)$ & Birth-12 months & $77(15.4)$ \\
\hline 30-39 years & $139(22.1)$ & 13-24 months & $280(56.6)$ \\
\hline v40-49 years & $55(8.7)$ & 25-34 months & $141(28)$ \\
\hline$v \geq 50$ years & $52(8.3)$ & Number of children & \\
\hline Marital status & & None & $23(4.7)$ \\
\hline Never married & $113(18)$ & One & $104(21.4)$ \\
\hline Married & $478(76)$ & Two & $115(23.7)$ \\
\hline Divorce & $17(2.7)$ & Three or more & $244(50.2)$ \\
\hline
\end{tabular}

Participant's education

No education

$73(11.6)$

Primary

Secondary

$218(34.8)$

$179(28.4)$

Higher education

Husband's education

No education

Primary

Secondary

Higher education

Religion

Protestant

Orthodox

Muslim

Catholic

Others

Ethnicity

Wolaita

Gamo

Garage

Amhara

vOthers

Occupational status of the women

House wife

Employee

Merchant

Student

Other

Age at which first pregnancy occurred

$$
\begin{aligned}
& \text { 15-24 years } \\
& \text { 25-34 years } \\
& \text { 35-44 years } \\
& \geq 45 \text { years }
\end{aligned}
$$

Table 1 Sociodemographic characteristics of the women in Wolaita Sodo, 2019 ( $n=629)$ (Continued)

previously heard of BSE were significantly associated with performing BSE $(p<0.05)$. Women who had mentioned BSE as a method for the early detection of breast problems were 6.36-times (95\% CI: 3.72, 10.71) more likely to perform BSE than those reported not knowing any method. Those who had breast fed for 13-24 months were 2.43 -times (95\% CI: $1.28,4.59)$ more likely to examine their breasts than those who mentioned different categories/duration of breast feeding. Employed study participants were 3.13-times more likely (95\% CI: $1.14,8.58)$ to practice BSE than those who were unemployed. Likewise, students were 3.73-times (95\% CI: $1.19,11.73)$ more likely to perform BSE than others (Table 5).

\section{Discussion}

This study showed that, in a random sample of women in an Ethiopian city, 94\% of respondents had ever heard or read about breast cancer. This figure is higher than the $83 \%$ reported for women in Mekelle town, northern Ethiopia [10] and lower than a study of female Malaysian students at 99.5\% [12]. These differences might reflect different educational levels among the study participants and/or differences in the study settings. We also found that $46 \%$ of women had previously heard about BSE, lower than in several other studies conducted in other countries: $78.4 \%$ in the Malaysian study [13], 67\% in Jordanian women [14], 47\% in undergraduate students in a teacher training college in Cameroon [15], $80.9 \%$ in Chinese immigrants [1], and $72.1 \%$ in women in a rural area of western Turkey [16]. However, awareness of BSE in our study was higher than in Benghazi, Libya, which showed that only $41.5 \%$ of women had heard of BSE [17]. These differences are likely to represent differences in socioeconomic and demographic characteristics of the study populations.

The relatively low knowledge of our respondents about BSE might prevent them from performing BSE, which might reduce chances of early detection of the disease. 


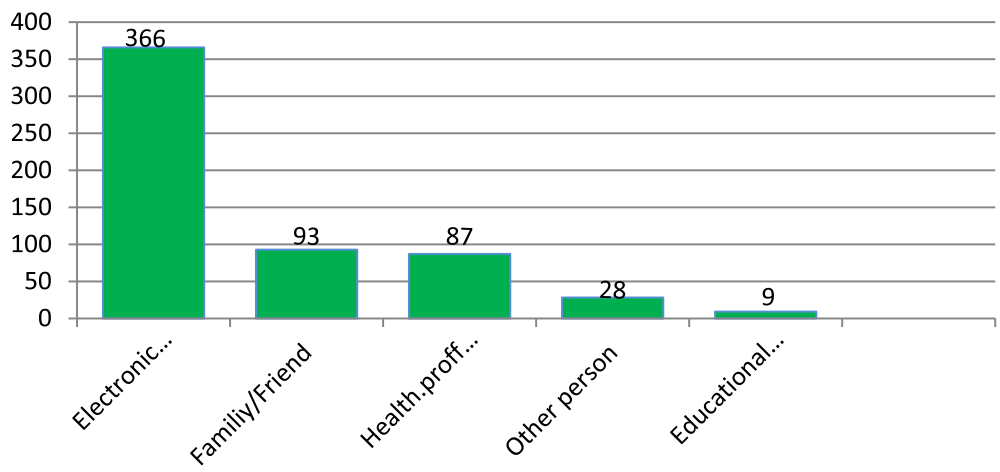

Fig. 2 Breast cancer information sources among women in Sodo city, 2019

$62 \%$ of our participants who had received breast cancer information indicated that their main source of information was from the media, with colleagues and friends also mentioned as important sources of information about breast cancer. Amazingly, the proportion of respondents who mentioned health professionals as a main source of breast cancer information was only $13.8 \%$. This is consistent with findings from a similar study conducted in Jordanian females where relatives, friends, and neighbors were found to be the main sources of breast cancer information [14] but different to a study of Iranian women, where health professionals were the main source of information (32.4\%) [18].

In the present study, $98 \%$ of breast cancer-informed participants knew that early detection of breast cancer improves chances of survival from the disease. This finding is supported by the study of Mekelle town women [10] and higher than a previous in western Ethiopia (74.7\%) [19]. Among respondents who reported to have had information on BSE, $79 \%$ had at some point performed BSE, lower than in a study of Nigerian Nurses in Lagos General Hospital (89\%) [4], and higher than studies of women in northern Ethiopia (37.3\%) [20], female Malaysian students (25.5\%) [12], female traders in Ibadan, Nigeria (18\%) [6], women in a rural area of western Turkey 40.9\% [16], and female household heads in northern Ethiopia (53.6\%) [10]. Our result was similar to that reported for female health professionals in Welega (77\%) [19]. Forty-five percent of our study sample performed BSE on a regular monthly basis, which is higher than in Jordanian women (only 7\%) [14], female Malaysian students (31.2\%) [12], and female undergraduate students in a teacher training college in Cameroon (25.9\%) [15]. This could be due to the different periods when these studies were conducted.

Twenty-nine percent of our participants knew the correct age at which BSE should be started, slightly greater women in Benghazi, Libya (27.7\%) [17] but fewer than those in south east Asia, where $44 \%$ of study participants recommended practicing BSE at age 20 [5], Nigerian women (60.28\% recommended age 20) [21], and women in Kyadondo County, Uganda (40\%) [22].

The different breast screening methods recognized by participants in the present study were BSE in $15.4 \%$ of women, clinical breast examination in $42.4 \%$, and mammography in $0.3 \%$.

Canadian women knew about BSE (64.3\%), clinical breast examination (45.7\%), and mammography (32.7\%) [20]. A study performed in northern Ethiopia on breast cancer screening methods reported by health extension workers were BSE (14.4\%), clinical breast examination (22.3\%), and mammography (3\%) [23]. These differences may be due to different educational levels and participant groups.

In this study, 53.6\% of women conducting BSE had support from their partners, which was higher than another study reporting that $39.8 \%$ of women performing BSE were getting support from their spouses/partners [24].

The major barriers to practicing BSE identified in the present study were pressure of work/being too busy, not having enough privacy to perform BSE, thinking that breast cancer wasn't possible, forgetfulness, and doubt about its effectiveness in 30 (13.8\%), 14 (6.4\%), 13 (5.9\%), $10(4.6 \%)$, and $11(5 \%)$ of respondents, respectively. However, over half of women performing BSE (119; 54.8\%) could not identify any obstacle to performing BSE. A study conducted in western Ethiopia reported that no current breast problem (12.7\%), not feeling comfortable performing BSE (2.7\%), scared of being diagnosed with breast problem or cancer, not believing it is beneficial $(4 \%)$, and not knowing how to do it (7.7\%) were barriers to not performing BSE [19].

In another study, the three main reasons for not performing BSE were no breast problem (53.2\%), not knowing the BSE technique (30.6\%), and not knowing the importance of BSE (21.4\%) [23]. In a study of female Debre Birhan University students, the main reasons for not performing BSE were a lack of knowledge on how to conduct BSE and not having any symptoms of breast cancer [25]. A study of female household heads in 
Table 2 Knowledge and practice of BSE and main information sources among women in Wolaita Sodo, $2019(n=629)$

\begin{tabular}{|c|c|}
\hline Characteristics/variables & Frequency (\%) \\
\hline \multicolumn{2}{|l|}{ Ever heard of breast cancer } \\
\hline Yes & $591(94)$ \\
\hline No & $38(6)$ \\
\hline \multicolumn{2}{|l|}{ Source of information } \\
\hline Electronic media & $366(62)$ \\
\hline Journal/brochure/leaflet/magazine & $4(0.8)$ \\
\hline Books & $3(0.5)$ \\
\hline Educational institution & $9(1.4)$ \\
\hline Non-governmental organizations & $1(0.2)$ \\
\hline Health workers & $87(14.7)$ \\
\hline Family/friend & $93(15.8)$ \\
\hline Other person & $28(4.7)$ \\
\hline \multicolumn{2}{|l|}{ Previously heard of BSE } \\
\hline Yes & $272(46)$ \\
\hline No & $319(54)$ \\
\hline \multicolumn{2}{|l|}{ Early detection method for breast cancer } \\
\hline Breast self-examination (BSE) & $107(18)$ \\
\hline Clinical breast examination (CBE) & $268(45.3)$ \\
\hline I don't know & $216(36.5)$ \\
\hline \multicolumn{2}{|l|}{ Performed breast self-examination } \\
\hline Yes & $217(78)$ \\
\hline No & $55(20.2)$ \\
\hline \multicolumn{2}{|l|}{ Still perform breast self-examination } \\
\hline Yes & $195(90)$ \\
\hline No & $22(10)$ \\
\hline
\end{tabular}

Knowledge that early detection of breast cancer improves chances of survival

$\begin{array}{ll}\text { Yes } & 570(96.7) \\ \text { No } & 13(2) \\ \text { I don't know } & 8(1.3) \\ \text { Family history of breast cancer } & \\ \text { Yes } & 14(2.4) \\ \text { No } & 523(88.6) \\ \text { I don't know } & 54(9) \\ \text { Personal history of having benign breast lamp } & \\ \text { Yes } & 20(3.3) \\ \text { No } & 197(33.3) \\ \text { I don't know } & 374(63.4)\end{array}$

Knowledge of someone suffering from breast cancer

Yes $116(20)$

No $475(80)$

Ever nursed a breast cancer patient

Yes 4 (1)

No 587 (99)
Table 2 Knowledge and practice of BSE and main information sources among women in Wolaita Sodo, $2019(n=629)$ (Continued)

\begin{tabular}{ll}
\hline Characteristics/variables & Frequency (\%) \\
\hline Had close contact with a person with a benign breast lamp \\
Yes & $18(3)$ \\
No & $573(97)$ \\
Knowledge of personal status of other body part cancer \\
Yes & $446(75)$ \\
No & $145(25)$ \\
Position of BSE & \\
Standing & $49(22.4)$ \\
Lying & $45(21)$ \\
Sitting & $16(7.3)$ \\
Standing and lying & $107(49.3)$ \\
Technical knowledge of BSE & \\
With palm and three middle fingers & $35(16)$ \\
Simply touch and feel & $157(72.5)$ \\
I don't know & $25(11.5)$ \\
BSE practices applied & \\
Inspection & $3(1.4)$ \\
Palpation & $116(53.6)$ \\
Inspection and palpation & $98(45)$ \\
Knowledge about which arm to be used for BSE & \\
Right hand for left breast and vice versa & $33(15)$ \\
The same arm for the same side breast & $13(6)$ \\
Any (no protocol) & $171(79)$ \\
\hline & \\
\hline
\end{tabular}

northern Ethiopia indicated that the major barriers to practicing BSE were an absence of symptoms and lack of knowledge about its importance [10].

Being healthy (44.8\%) and a lack of knowledge about BSE (26.9\%) were the most significant barriers mentioned for not practicing BSE at Adama Science and Technology University [11].

The current study revealed that women who recognized BSE as an early breast cancer detection method were 6.36-times more likely to practice BSE than women who did not know of any methods to detect breast cancer. This finding is consistent with a study of women in Malaysia, which showed that knowledge that BSE is an early detection method for breast cancer was significantly associated with BSE [13].

In the current study, being employed in an occupation other than being a housewife was significantly associated with performing BSE, with these women 3.12-times (95\% CI: 1.14, 8.58) more likely to practice BSE than other groups. These results are in agreement with findings in Nigerian women [26], a study in Benghazi, Libya [17], and a study from southern Ethiopia [24]. This may 
Table 3 Distribution of time BSE practiced, and the reasons given to perform or not perform BSE among women in Wolaita Sodo, $2019(n=626)$

\begin{tabular}{ll}
\hline Variable/characteristics & Frequency (\%) \\
\hline Appropriate time of BSE & \\
Few days after menses & $97(45)$ \\
Few days before menses & $13(6)$ \\
No specific time & $107(49)$ \\
Frequency of BSE practices & \\
Twice per month & $48(22.2)$ \\
Once every month & $98(45)$ \\
Once every 6 month & $2(0.9)$ \\
Once per year & $4(1.9)$ \\
Any time I observe a change & $65(30)$ \\
Advantage of regular breast self-examination & \\
Detect any abnormality & $72(33)$ \\
Learn how the breast normally looks and feels & $56(26)$ \\
Detect breast cancer earlier and promote treatment & $89(41)$ \\
Reasons for performing BSE & \\
Fear of breast cancer & $51(23.5)$ \\
Early detection of breast cancer & $128(59)$ \\
Breast cancer in the family/friends & $13(6)$ \\
Previous breast problems & $3(1.4)$ \\
Heard from media & $22(10)$ \\
Barriers to BSE & $13(6)$ \\
I don't have enough privacy for BSE practice & $119(54.8)$ \\
I koubse obstacle (barriers) & $14(6.4)$ \\
\hline & $30(13.8)$ \\
I worg scared of being diagnosed with breast cancer & $11(5)$ \\
\hline
\end{tabular}

Table 4 Distribution of spousal/parental support to perform BSE and the need for further information among women in Wolaita Sodo, $2019(n=626)$

\begin{tabular}{ll}
\hline Variables/characteristics & Frequency (\%) \\
\hline Support on BSE from spouse/partner & $146(67.2)$ \\
Yes & $71(32.8)$ \\
No & \\
Would like information on how to do BSE & $249(91)$ \\
Yes & $23(9)$ \\
No & \\
Recognized importance of BSE & $207(95.3)$ \\
Very important & $10(4.7)$ \\
Important & \\
Self-confidence to perform BSE & $191(88)$ \\
Yes & $26(11)$ \\
No & \\
Where will you go, if you discover a breast lump & $168(77.4)$ \\
Health facility & $49(22.6)$ \\
Traditional healer &
\end{tabular}

due to these other occupations exposing these women to a wider selection of media, friends, and colleagues to share ideas and experiences and initiating BSE practice.

Women who had breast fed their child for 13-24 months were 2.43-times more likely to examine their breasts than those who mentioned different durations of breast feeding, which may be due to those who optimally breast feed being more conscious of or educated to perform BSE.

Women who used electronic media as a source of information were 1.59-times more likely to practice BSE than women who used other media types. This may be due to its relative accessibility compared to other source of information.

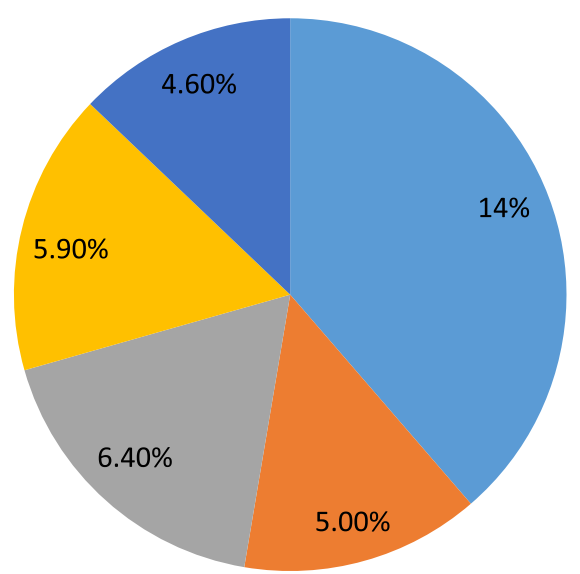

- Too busy

Doubt about its effectiness

I do not have enough privacy to BSE

- I know I can never have Bca

- Forgetfulness

Fig. 3 Reasons of not performing Breast self-examination 
Table 5 Factors associated with breast self-examination among women in Wolaita Sodo, 2019 ( $n=626)$

\begin{tabular}{|c|c|c|c|c|}
\hline \multirow[t]{2}{*}{ Variables } & \multicolumn{2}{|l|}{ Perform BSE } & \multicolumn{2}{|c|}{ Odds ratio $(95 \% \mathrm{Cl})$} \\
\hline & Yes & No & $\operatorname{COR}(95 \% \mathrm{Cl})$ & AOR $(95 \% \mathrm{Cl})$ \\
\hline \multicolumn{5}{|c|}{ Participant's occupation status } \\
\hline House wife & $96(15 \%)$ & $217(34.4 \%)$ & 1.00 & 1.00 \\
\hline Employee & $76(12 \%)$ & $57(9 \%)$ & $2.07(1.20,3.59)$ & $3.13(1.14,8.58)$ \\
\hline Merchant & $26(4 \%)$ & $49(7.7 \%)$ & $6.25(3.42,11.41)$ & $6.47(2.31,18.12)$ \\
\hline Student & $19(3 \%)$ & $89(14 \%)$ & $2.49(1.25,4.94)$ & $3.73(1.19,11.73)$ \\
\hline \multicolumn{5}{|l|}{ Duration breastfeeding } \\
\hline Birth-12 months & $39(7.8 \%)$ & $39(7.8 \%)$ & 1.00 & 1.00 \\
\hline 13-24 months & $101(20 \%)$ & $181(36.4 \%)$ & $2.10(1.18,0.74)$ & $2.43(1.28,4.59)$ \\
\hline $25-34$ months & $46(9.2 \%)$ & $92(18.4 \%)$ & $1.16(0.75,0.78)$ & $1.19(0.74,1.92)$ \\
\hline \multicolumn{5}{|c|}{ Early detection method for breast cancer } \\
\hline BSE & $111(32 \%)$ & $9(33 \%) 364$ & $7.03(4.14,11.95)$ & $6.36(3.72,10.71)$ \\
\hline I don't know & $106(20 \%)$ & (59\%) & 1.00 & 1.00 \\
\hline \multicolumn{5}{|c|}{ Personal history of having benign breast lump } \\
\hline Yes & $21(3.5 \%)$ & $59(10 \%)$ & $2.31(1.20,4.46)$ & $0.03(0.08,1.52)$ \\
\hline No & $196(33 \%)$ & $315(53 \%)$ & 1.00 & 1.00 \\
\hline \multicolumn{5}{|c|}{ Women's educational status } \\
\hline Primary & $82(28.2 \%)$ & $209(71.8 \%)$ & 1.00 & 1.00 \\
\hline Secondary & $135(39.9 \%)$ & $203(60.1 \%)$ & $1.70(1.21,2.37)$ & $0.81(0.29,2.24)$ \\
\hline \multicolumn{5}{|c|}{ Husband's educational status } \\
\hline Primary & 51 & 118 & 1.00 & $0.62(0.26,1.49)$ \\
\hline Secondary & 134 & 175 & $1.80(1.21,2.67)$ & \\
\hline \multicolumn{5}{|l|}{ Source of information } \\
\hline Electronics media & $151(25.5 \%)$ & $218(36.8)$ & $1.63(1.14,2.32)$ & $1.59(1.01,2.59)$ \\
\hline Other & $66(11 \%)$ & $156(26.3)$ & 1.00 & 1.00 \\
\hline
\end{tabular}

Adjusted odds ratio (AOR), Significant at $p-\leq 0.05$

\section{Strengths and limitations of the study}

The main strength of the study is that previous studies conducted in Ethiopia focused on health professionals, whereas we studied a general urban community. However, this study was limited by being conducted in a single urban community, which may not be representative of the rural community or other urban communities in Ethiopia. Since this was a cross-sectional study, causal conclusions cannot be drawn.

\section{Conclusion}

In general, a low proportion of participants had previously heard about BSE. Only about half of participants performed BSE regularly, and less than a third of respondents correctly recognized the age at which BSE should commence. The use of electronic media as a source of information, occupation, and knowledge about early detection methods for breast cancer were associated with performing BSE. Therefore, we recommend that the Wolaita Sodo administration needs to use electronic media consistently and programmatically (e.g.,
Wolaita Sodo Fana FM, Wolaita Sodo Wogeta FM, and South TV) to advocate performing BSE. Weekly or monthly mobile phone messages could be sent to encourage performing BSE. Video screens could be used in the city center to demonstrate BSE issues. The advantage of performing BSE over other early screening methods must also be emphasized in public health campaigns.

\section{Abbreviations \\ AOR: adjusted odds ratio; BSE: breast self-examination; CBE: clinical breast examination; Cl: confidence interval; OR: odds ratio}

\section{Acknowledgments}

We would like to thank Wolaita Sodo University, College of Health Sciences and Medicine. We also thank Wolaita Zone administrators, the supervisors, respondents, and data collectors.

\section{Authors' contributions}

$T L$ and $A B$ were involved in proposal writing, designed the study and participated in coordination, analyzed the data, drafted and finalized the manuscript. SA and BB conceived the study and participated in all stages of the study and revision of the manuscript. All authors read and approved the final version of the manuscript. 
Funding

This study was not funded.

\section{Availability of data and materials}

The data for this research is available on request. Someone who wants data of this study can contact corresponding author.

\section{Ethics approval and consent to participate}

Ethical clearance and approval was obtained from Wolaita Sodo University Institutional Review Board and a letter of cooperation was established between the Wolaita Sodo University College of Health Science and Medicine and Wolaita Sodo Health Bureau. Written consent was obtained from study participants after explaining the study objectives and procedures, and their right to refuse not to participate in the study any time was assured. For this purpose, a one page consent letter was attached to the cover page of each questionnaire stating the general objective of the study and issues of confidentiality, which were also discussed by the data collectors before proceeding with the interview. Confidentiality of the information was ensured by coding. The interview was undertaken privately in an area separated from others. Only authorized individuals were given access to the raw data collected from the field.

\section{Consent for publication}

Not applicable.

\section{Competing interests}

The authors have declared that no competing interests exist.

\section{Author details}

${ }^{1}$ School of Public Health, Wolaita Sodo University, Wolaita, Ethiopia. ${ }^{2}$ South Ethiopia Nations Development Association, Wolaita Sodo, Wolaita, Ethiopia.

Received: 13 September 2019 Accepted: 30 July 2020

Published online: 08 August 2020

\section{References}

1. Fung S. Factors associated with breast self-examination behaviour among Chinese women in Hong Kong," Patient Education and Counseling 1998. pp. 233-43.

2. Bray FRJ, Masuyer E, Ferlay J. Global cancer prevalence for 27 sites in the adult population in 2008. Int J Cancer. 2013;132(5):1333-145.

3. International Agency for Research on Cancer ( IARC). Breast Cancer Incidence, Mortality and Prevalence Worldwide. Available at: www@iarc 2008. 2008 .

4. Ibrahim NAOO. Knowledge of risk factors, beliefs and practices of female healthcare professionals towards breast cancer in a tertiary institution in Lagos, Nigeria. BMC Cancer. 2009:9(1):76.

5. Ginseng GM LJ, Zelle S, Baeten,et al. Cost effectiveness of strategies to combat breast, cervical, and colorectal cancer in Sub-Saharan Africa and South East Asia. Mathematical modelling study BMJ. 2012;344:614.

6. Balogun MO OE. Knowledge and practice of BSE among female Trader in Ibadan,. Nigeria Ann Ibadan Postgraduate Med. 2005;3(2):52-56.

7. Dye TD BS, Hobden C, Tilahun Y, et al. Experience of Initial Symptoms of Breast Cancer and Triggers for Action in Ethiopia. Int. J. Breast Cancer. https://www.hindawi.com/journals/ijbc/2012/908547/abs/.Volume 2012 (2012).

8. The American Cancer Society. Breast Cancer prevention and early detection duidelines. 2014

9. Wolaita Zone Finance, Socio Economic and Population report, 2017/2018 p 49

10. Befikadu L TG. Knowledge on breast cancer and its prevention among women household heads in Northern Ethiopia. Vol4, No1. 2014.

11. Mesfin TDM, Roza A, et al. Breast self-examination: knowledge, attitude, and practice among female health science students at Adama science and Technology University, Ethiopia. Gynecol Obstet (Sunnyvale). 2016;2016.

12. Akhtari-Zavare $M$, Juni $M H$, Ismail IZ, et al. Barriers to breast self-examination practice among Malaysian female students: a cross sectional study. Springer Plus. 2015;4:692. https://doi.org/10.1186/s40064-0151491-8.

13. Redhwan Ahmed Al-Naggar1, Yuri V Bobryshev, Karim Al-Jashamy. Practice of Breast Self-Examination among Women in Malaysia.2012. DOl:http:// dxdoiorg/107314/APJCP20121383829.
14. Hadayat A-RA. Breast self-examination and risk factors of breast cancer: Awareness of Jordanian nurses. Health Sci J. 2013;7(2013).

15. Carlson-B S BD, Jules Awareness of breast cancer and breast selfexamination among female undergraduate students in a higher teachers training college in Cameroon. Pan African Med J. 2017:p 3-4. 16.

16. Dündar $\mathrm{PE}$, et al. The knowledge and attitudes of breast self-examination and mammography in a group of women in a rural area in western Turkey. BMC Cancer. 2006;6:43.

17. Ziuo FM TA, Huria et al. . Low awareness about breast self examination and risk factors of breast cancer in Benghazi, Libya. Ibnosina J Med Biomed Sci 2018.10:54-59.

18. Sadigheh Sadat Tavafian, Laleh Hasani, Teamur Aghamolaei, Shahram Zare et al. Prediction of breast self-examination in a sample of Iranian women: an application of the Health Belief Model. BMC Women's Health. 2009;9, article page 37.

19. Elias L. N WDH, Alemu S. M. Assessment of breast self-examination practice and associated factors among female health professionals in Western Ethiopia. http://www.academic.journals.org/IJMMS 2016;9(12).

20. Maxwell CJ, Bancej CM, Snider J. Predictors of mammography use among Canadian women aged 50-69: findings from the 1996/97 National Population Health Survey. CMAJ. 2001;164:329-34

21. Okobia MN BC, Okonufua FE, $\mathrm{O}$ et al. Knowledge, attitude and practice of Nigerian women towards breast cancer: a cross sectional study. World J Surg Oncol 2006:4:11.

22. Wabinga HR, Parkin DM, Wabwire-Mangen F, Nambooze S. Trends in cancer incidence in Kyadondo County, Uganda, 1960-1997. Brit J Cancer. 2000; 82(9):1585-92.

23. Azage M AG, Mekonnen A et al. Assessment of factors associated with breast self-examination among health extension workers in West Gojjam Zone, Northwest Ethiopia. IntJBreastCancer2013:814395Availableat: https:// www.hindawi.com/journals/ijbc/2013/814395. 2013.

24. Minasie AHB, Abraham A. Breast self-examination practice among female health extension workers. ReprodSyst Sex Disord. 2017;6:219.

25. Kalayu $B$, et al. Practices of Breast Self-Examination and Associated Factors among Female DebreBerhan University Students. Int J Breast Cancer. 2017; 5842017:6.

26. Odusanya O०, Tayo O०. Breast Cancer knowledge, attitudes and practice among nurses in Lagos, Nigeria. Acta Oncol. 2001;40(7):844-8. https://doi. org/10.1080/02841860152703472

\section{Publisher's Note}

Springer Nature remains neutral with regard to jurisdictional claims in published maps and institutional affiliations.

Ready to submit your research? Choose BMC and benefit from:

- fast, convenient online submission

- thorough peer review by experienced researchers in your field

- rapid publication on acceptance

- support for research data, including large and complex data types

- gold Open Access which fosters wider collaboration and increased citations

- maximum visibility for your research: over $100 \mathrm{M}$ website views per year

At BMC, research is always in progress.

Learn more biomedcentral.com/submission 